\title{
Şehiriçi Toplu Taşıma Araçlarını Kullanan Şoförlerde Kardiyovasküler Risk Faktörleri, Fiziksel Aktivite Düzeyi Ve Anksiyete Durumunun Değerlendirmesi
}

Examination of Cardiovascular Risk Factors, Physical Activity Level and Anxiety of Urban Public Transport Drivers

\author{
Saniye AYDOĞAN ARSLAN', Arzu DAŞKAPAN², Meral SERTER², Fatih KURTOĞLU \\ ${ }^{1}$ Dr. Fzt., Kırıkkale Üniversitesi, Sağlık Bilimleri Fakültesi, Fizyoterapi ve Rehabilitasyon Bölümü, Kırıkkale \\ ${ }^{2}$ Prof. Dr., Kırıkkale Üniversitesi, Sağlık Bilimleri Fakültesi, Fizyoterapi ve Rehabilitasyon Bölümü, Kırıkkale \\ ${ }^{3}$ Fzt., Kırıkkale Üniversitesi, Sağlık Bilimleri Fakültesi, Fizyoterapi ve Rehabilitasyon Bölümü, Kırıkkale
}

öz

Amaç: Çalışmamızın amacı; Kırıkkale ilinde şehir içi minibüs şoförlerinde değiştirilebilir Kardiyovasküler hastalık risk faktörlerinin fiziksel aktivite düzeyinin ve anksiyete durumunun belirlenmesiydi. Gereç ve Yöntem: Katılımcıların sosyo demografik bilgileri kaydedildi. Sigara, egzersiz alışkanlığı sorgulandı ve vücut kütle indeksi belirlendi. Anksiyete durumu Beck Anksiyete Ölçeği ve fiziksel aktivite düzeyi Uluslararası Fiziksel Aktivite Anketi (UFAA) ile değerlendirildi. Sonuçlar: Çalışmamıza 250 gönüllü minibüs şoförü katıldı (yaş ortalaması, $39.33 \pm 10.86$ yıl). UFAA puanları dikkate alındığında, bireylerin \% 5,2'sinin yeterli fiziksel aktivite düzeyine sahip olduğu görülmüştür. Şoförler \% 64,8 i kalp hastalığının önlenebileceğini düzenli egzersiz yapmanın önemini belirtti. Anksiyete durumları ile fiziksel aktivite düzeyleri arasında ilişki saptanmadı. Tartışma: Kardiyovasküler hastalık gelişimi, özellikle tütün kullanımı, sağlıksız beslenme alışkanlıkları, fiziksel inaktivite ve psikososyal stress gibi yaşam tarzını belirleyen faktörler ile yakından ilişkilidir. Katılımcıların genç yaş ortalamasına rağmen, kalp damar hastalıkları, obesite, hipertansiyon gibi sorunlara rastlanmıştır. Tüm bu sağlık sorunlarının önlenebilmesinde sağlıklı yaşam tarzının benimsenmesi en önemli rolü oynamaktadır.

Anahtar Kelimeler: Şoförler; Kardiyovasküler risk faktörleri; Fiziksel aktivite

\section{A B S T R AC T}

Purpose: Purpose of this study is to examine the alterable cardiovascular risk factors of urban minibus drivers in the city of Kırıkkale, and to determine physical activity levels and anxiety statuses. Material and Methods: Their socio-demographic data were recorded. Drivers' habits of smoking and exercise were questioned and their body mass indexes were determined. Anxiety statuses were assessed by using Beck Anxiety Scale and physical activity levels were assessed by using International Physical Activity Questionnaire. Results: 250 volunteering minibus drivers (mean age 39.33 10.86 ) were participated to the study. Regarding their UFAA scores, $5.2 \%$ of the individuals had adequate physical activity levels. $64.8 \%$ of participants thought the cardiovascular diseases could be prevented and $31.6 \%$ implied the importance of regular exercise program. There was no relationship between physical activity and anxiety. Conclusionon: Cardiac diseases are closely related with life style factors such as; smoking, unhealthy eating habits, physical inactivity, and psycho-social stress. Ailments like; cardiovascular diseases, obesity, hypertension were observed, although the participants had a young mean age. Adopting a healthy life style plays the most important role in preventing all these health problems.

Keywords: Driver, Cardiovascularrisk factors; Physical Activity 
Dünya Sağlık Örgütü (DSÖ), sağlığı bireyin bedensel, ruhsal ve sosyal açıdan tam bir iyilik durumu olarak tanımlamaktadır. Bu tanım çerçevesinde kişinin sağlık durumu, meslek, çalışma koşulları, yaşanılan yer, ekonomik düzey gibi pek çok faktörden etkilenmektedir (WHO, 2006). Kardiyovasküler hastalıklar (KVH) dünya çapında, mortalite ve morbiditenin majör nedeni olarak kabul edilmektedir ( Mitka, 2004; Callow, 2006). KVH'ın 20. yüzyılın başlarında tüm dünyadaki ölüm nedenlerinin \%10'undan daha azını oluşturduğu, bu oranın zaman içinde giderek arttığı ve 21 . yüzyıIın başından itibaren gelişmiş ülkelerdeki ölümlerin \%50'sinden, gelişmekte olan ülkelerde ise \%25'inden sorumlu olduğu rapor edilmektedir (Mutangadura ve Gladys, 2002).

KVH'ın önlenmesi ve prevalansının azaltılması amacıyla risk faktörlerinin belirlenmesi ve yönetimi sağlığın korunmasında öncelikli konular arasında yer almaktadır (Sofi, Cesari, Abbate ve ark, 2008). Sigara içme, hipertansiyon, obezite, Diyabetes mellitus hastalığı, fiziksel aktivite azlığı ve yanlış diyet değiştirilebilir risk faktörleri olarak bilinmektedir. (Mendis, Puska ve Norrving, 2011).

Ülkemizde KVH konusunda geniş çaplı bir prevelans araştırması olan Türk Erişkinlerinde Kalp Hastalıkları ve Risk Faktörleri (TEKHARF) çalışmasına göre, 2000'li yıllarda kalp hastalıkları sıklığı \% 8,1 oranlarına ulaşarak, bilinen ölüm nedenleri arasında ilk sırada yer almaktadır. TEKHARF çalışmasına göre sigara kullanımı, hipertansiyon, kolesterol yüksekliği, diyabet, ve obesite sık görülen değiştirilebilir risk faktörleri arasındadır. (Onat, Keleş, Çetinkaya ve ark, 2001).

Mesleğin sürdürüldüğü çalışma hayatı, insan yaşamının en merkezi alanlarından biridir. (ArsIan, Koz, Gür ve ark, 2003). Çağımızın yaşam ve iş koşulları insanları daha az hareket eder duruma getirmektedir. Ayrıca iş hayatında rekabet, stres gibi faktörler, kalp sağlığını olumsuz etkilemektedir. Minibüs şoförlüğü, uzun süre hareketsiz kalmayı gerektiren, çeşitli stres etkenlerinin eşlik ettiği (egzoz gazına maruz kalma, orta-düşük gelir düzeyi, güvenli olmayan trafik davranışları), uyku saatlerinin düzensiz olduğu ağır çalışma şartları içinde sürdürülen bir meslektir. Şoförlerde kalp damar hastalıkları, mide-barsak rahatsızlıkları, kas iskelet sistemi problemleri, depresyon ve anksiyete durumlarının ortaya çıkma riskinin diğer mesleklere göre daha yüksek olduğu bildirilmektedir (Zhou, Zheng, Bai ve ark, 2014; Shin, Lee, Song ve ark, 2013).

Çalışmamızın amacı; Kırıkkale ilinde şehir içi minibüs şoförlerinde değiştirilebilir KVH risk faktörlerinin sorgulanması, fiziksel aktivite düzeyinin ve anksiyete durumunun belirlenmesiydi.

\section{GEREÇ VE YÖNTEM}

Çalışmamıza Kırıkkale il Merkezi'nde Kırıkkale Şoförler ve Minibüsçüler Odası'na kayıtlı olan ve gönüllü tüm şoförler dahil edildi. Araştırmanın yürütülmesi konusunda Kırıkkale Üniversitesi Klinik Araştırmalar Etik Kurulu'ndan gerekli izin alındı (28/03.15.12.2015). Çalışma gönüllülere ilan yoluyla duyuruldu. Tüm gönüllülerden aydınlatılmış onam belgesi alındı.

Çalışmada kişilerle yüz yüze görüşme tekniği kullanılarak sorgulamalar tamamlandı. KatılımclIarın sosyo demografik bilgileri ve şoförlük süresi kaydedildi. Değerlendirme kapsamında doktor tarafından tanısı konan ve/veya düzenli ilaç ile kontrol gerektiren hastalıklar hakkında bilgi edinildi. Değiştirilebilir KVH risk faktörleri kapsamında, sigara, egzersiz alışkanlığı sorgulandı ve vücut kütle indeksi (VKi) belirlendi. Tüm bireylerin ve vücut ağırığı ölçümleri Tanita BC 730 marka tartı ile yapılmıştır. Anksiyete durumu Beck Anksiyete Ölçeği (BAÖ) ve fiziksel aktivite düzeyi Uluslararası Fiziksel Aktivite Anketi (UFAA- kısa form) ile değerlendirildi.

Ayrıca, "Kalp hastalığı önlenebilir mi?" sorusu sorularak ve kalp hastalığının önlenmesine yönelik literatürde belirtilen öncelikli üç sağlıklı yaşam tarzının (egzersiz yapmak, sigara bırakmak ve doğru beslenme) sıralanması istendi (Amine, Baba, Belhadj ve ark., 2002).

Fiziksel Aktivite Anketi: Fiziksel aktivite düzeyleri Türkçe geçerlilik ve güvenirlilik çalışması yapılmış olan uluslararası fiziksel aktivite anketi (UFAA- kIsa form) ile belirlendi. Anket yedi sorudan oluşmaktadır yürüme, orta düzeyde şiddetli aktiviteler ve şiddetli aktivitelerde harcanan zaman yürüme ve oturma hakkında bilgi vermektedir. Toplam skorunun hesaplanması, yürüme, orta düzeyde şiddetli aktivite ve şiddetli aktivitenin süre (dakikalar) ve frekans (günler) toplamını içermektedir. Oturma puanı (sedanter davranış düze- 
yi) ayrı olarak hesaplanmaktadır. Bütün aktivitelerin değerlendirilmesinde her bir aktivitenin tek seferde en az 10 dakika yapılıyor olması ölçüt alınmaktadır. Dakika, gün ve MET değeri (istirahat oksijen tüketiminin katları) çarpılarak "MET-dakika/ hafta" olarak bir skor elde edilmektedir. Yürüme puanının hesaplanmasında yürüme için 3.3 MET, orta düzeyde şiddetli aktivite için 4 MET, şiddetli aktivite için 8 MET değeri alınmaktadır. Ankete göre, fiziksel aktivite düzeyleri, fiziksel olarak aktif olmayan ((6000 MET-dk/hafta), fiziksel aktivite düzeyi düşük olan (600-3000 MET-dk/hafta) ve fiziksel aktivite düzeyi yeterli olan (sağlık açısından yararlı olan) (>3000 MET-dk/hafta) şeklinde sınıflandırılmıştır (Sağlam, Arıkan, Savcı ve ark, 2010).

Beck Anksiyete Ölçeği (BAÖ), Beck ve arkadaşları (1988) tarafından geliştirilen bireylerin yaşadığı anksiyete belirtilerinin sıklığının belirlenmesi amacıyla kullanılan kendini değerlendirme ölçeğidir. 21 maddeden oluşan, 0-3 arası puanlanan likert tipi bir ölçektir. Toplam puanın yüksekliği kişinin yaşadığı anksiyetenin yüksekliğini gösterir. Türkiye'de geçerlik ve güvenirliği Ulusoy ve arkadaşları (1998) tarafından yapılmıştır (Beck, Epstein, Brown ve ark, 1988; Ulusoy, Şahin, Erkman, 1998).

\section{İstatistiksel Analiz}

Verilerin analizi SPSS 17.0 ( SPSS Inc., Chicago, Illionis, ABD) programı ile yapıldı. Tanımlayıcı istatistikler ortalama \pm standart sapma (ortalama \pm ss) biçiminde verildi. Kategorik veri analizi Ki-Kare testi ile değerlendirilmiştir (Alpar, 2012).

\section{SONUÇLAR}

Çalışmamız Kırıkkale Şoförler ve Minibüsçüler Odası'na kayıtı olan 400 minibüs şoförü arasından gönüllü 250 şoför (yaş ortalaması, 39.33 \pm 10.86 yıl) ile tamamlandı. Katılımcıların sosyo demografik verileri Tablo 1' de özetlendi. Bireylerin kardiyovasküler risk faktörleri Tablo 2' de belirtildi.

UFAA puanları dikkate alındığında, bireylerin $\%$ 5,2'sinin yeterli fiziksel aktivite düzeyine sahip olduğu görüldü (Tablo 3).

Bireylerin BAÖ ve UFAA verileri Tablo 4' te gösterildi.

Çalışmamızda anksiyete durumları ile fiziksel aktivite düzeyleri arasında ilişki saptanmadı (Tablo 5).
Çalışmamıza katılan şoförlere "kalp hastalığı önlenebilir mi?" sorusu soruldu ve bireylerin \%64,8'i "evet" , \%10,8'i "hayır" , \%24,4'ü ise "bilmiyorum" cevabını verdi (Tablo 6).

Çalışmaya katılan şoförlere "Kalp hastalığını önlemede öncelikli davranışlar nelerdir" sorusu sorulduğunda\%31.6'sının cevabının "düzenli egzersiz yapmak" olduğu görüldü (Tablo 7 ).

\section{TARTIŞMA}

Kardiyovasküler hastalıkları gelişimi, özellikle tütün kullanımı, sağlıksız beslenme alışkanlıkları, fiziksel inaktivite ve psikososyal stress gibi yaşam tarzını belirleyen faktörler ile yakından ilişkilidir (Amine, Baba, Belhadj ve ark. 2002). Yoğun iş temposu ve yollarda sağlıklı besin tercihi yapabilme ile egzersiz imkânı yaratabilme konusundaki kısıtlılıklar, şoförlerde sağlıksız yaşam stiline katkıda bulunmaktadır. Hirata ve arkadaşları, taşımacılık sektöründe çalışan kişilerde yanlış beslenme ve sedanter yaşam tarzı riskinin yüksek olduğunu rapor etmektedir (Hirata, Sampaio, LeitaoFilho ve ark, 2012 ).

Kırıkkale ilinde toplu taşımada önemli yeri olan minibüslerin şoförlerini kapsayan araştırmamızda, şoförlerin kalp damar hastalığı gelişim riskleri konusunda fikir sahibi olmak istenmiştir. Bu amaçla, yaşam tarzı ile doğrudan ilişkili olan değiştirilebilir risk faktörlerine yer verilmiş, aynı zamanda fiziksel aktivite düzeyleri ve anksiyete durumları belirlenmiştir.

Literatürde farklı ülkelerde tamamlanan, şoförleri kalp damar hastalıkları gelişim sıkığı, riski ve bu riski belirleyen faktörler açısından ele alan çalışmaların önemli bir yer tuttuğu dikkati çekmektedir.( Ueda, Hashimoto, Yasui ve ark, 1989; Hattori, 1989). Raporlara göre, sürücülerde KAH görülme oranı, ofis çalışanları ve sanayi işçilerine göre daha yüksektir. (Bigert, Gustavsson, Hallqvist ve ark, 2003; Apantaku-Onayemi, Baldyga, Amuwo ve ark; 2012). Benzer olarak; Japonyada taksi şoförlerinde kalp damar hastalıkları gelişimini değerlendiren araştırmaların sonuçları Japon taksi şoförlerinde KVH gelişim riskinin yüksek olduğuna dikkat çekmektedir (Hattori, 1988; Ueda, Hashimoto, Yasui ve ark, 1989; Hattori, 1989).

İlimizde minibüs şoförleri arasında gerçekleştirdiğimiz araştırma sonuçlarına göre, $\mathrm{KAH}^{\prime}$ na sahip olma oranı sadece $\% 6$ olarak saptanmıştır. Bu 
Tablo 1. Bireylerin sosyo-demografik verileri

\begin{tabular}{|c|c|}
\hline & $(n=250)$ \\
\hline 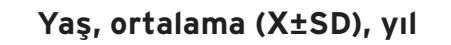 & $39.33 \pm 10.86$ \\
\hline 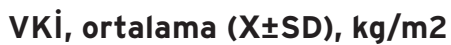 & $27.10 \pm 4.27$ \\
\hline \multicolumn{2}{|l|}{ Vki, n (\%) } \\
\hline Zayıf & $1(0.4)$ \\
\hline Normal & $70(28.0)$ \\
\hline Fazla kilolu ve obez & $179(71.6)$ \\
\hline \multicolumn{2}{|l|}{ Medeni durum, n (\%) } \\
\hline Evli & $194(77.6)$ \\
\hline Bekar & $56(22.4)$ \\
\hline \multicolumn{2}{|l|}{ Eğitim durumu, n (\%) } \\
\hline Okuryazar değil & $7(2.8)$ \\
\hline ilkokul & $61(24.4)$ \\
\hline Ortaokul & $86(34.4)$ \\
\hline Lise & $83(33.2)$ \\
\hline Üniversite ve üstü & $13(5.2)$ \\
\hline
\end{tabular}

Tablo 3. Bireylerin Uluslararası Fiziksel Aktivite Anketi'nden (UFAA) elde edilen fiziksel aktivite düzeyleri

\begin{tabular}{|c|c|}
\hline Fiziksel aktivite düzeyleri (n/\%) & $\mathrm{n}=250$ \\
\hline Fiziksel olarak aktif olmayan & $120(48)$ \\
\hline Fiziksel aktivite düzeyi düşük olan & $117(46.8)$ \\
\hline Fiziksel aktivite düzeyi yeterli olan & $13(5.2)$ \\
\hline
\end{tabular}

$* p<0.05$

Tablo 4. Bireylerin BAÖ ve UFAA verileri

\begin{tabular}{|c|c|}
\hline Değişkenler & ort \pm ss \\
\hline BAÖ & $7.02 \pm 6.30$ \\
\hline UFAA & $988.94 \pm 1080.01$ \\
\hline
\end{tabular}

BAÖ: Beck anksiyete ölçeği; UFAA: Uluslararası fiziksel aktivite anketi

Tablo 5. BAÖ ve UFAA arasındaki ilişkisi

\begin{tabular}{|c|c|c|}
\hline Değişkenler & $\begin{array}{c}\text { BAÖ } \\
\mathbf{r ( p )}\end{array}$ & $\begin{array}{c}\text { UFAA } \\
\mathbf{r ( p )}\end{array}$ \\
\hline BAÖ & - & $-0.006(0.930)^{*}$ \\
\hline UFAA & $-0.006(0.930)^{*}$ & \\
\hline
\end{tabular}

*p<0.05. r: Pearsonkorelasyon katsayısı.

BAÖ: Beck anksiyete ölçeği; UFAA: Uluslararası fiziksel aktivite anketi
Tablo 2. Bireylerin kardiyovasküler risk faktörleri $(n=250)$

\begin{tabular}{|c|c|}
\hline Kalp damar rahatsızlığı, n (\%) & \\
\hline Evet & $15(6.0)$ \\
\hline Hayır & $206(82.4)$ \\
\hline Bilmiyorum & $29(11.6)$ \\
\hline \multicolumn{2}{|l|}{ Tansiyon rahatsızlığı,n (\%) } \\
\hline Yüksek tansiyon & $23(9.2)$ \\
\hline Düşük tansiyon & $15(6.0)$ \\
\hline Herhangi bir rahatsızlığım yok & $157(62.8)$ \\
\hline Bilmiyorum & $55(22.0)$ \\
\hline \multicolumn{2}{|l|}{ Diyabet rahatsızı̆ı̆ı, n (\%) } \\
\hline Evet & $20(8.0)$ \\
\hline Hayır & $207(82.8)$ \\
\hline Bilmiyorum & $23(9.2)$ \\
\hline \multicolumn{2}{|l|}{ Sigara, n (\%) } \\
\hline Hiç içmedim & $69(27.6)$ \\
\hline Ara sıra içiyorum & $47(18.8)$ \\
\hline Düzenli içiyorum & $116(46.4)$ \\
\hline İçiyordum bıraktım & $18(7.2)$ \\
\hline \multicolumn{2}{|l|}{ Düzenli egzersiz alışkanlığı, n (\%) } \\
\hline Evet & $29(11.60)$ \\
\hline Hayır & 221(88.40) \\
\hline
\end{tabular}

Tablo 6. Kalp hastalığı önlenebilir mi?

\begin{tabular}{|c|c|}
\hline & N (\%) \\
\hline Evet & $162(64.8)$ \\
\hline Hayır & $27(10.8)$ \\
\hline Bilmiyorum & $61(24.4)$ \\
\hline
\end{tabular}

Tablo 7. Kalp hastalığını önlemede öncelikli davranışlar nelerdir?

\begin{tabular}{|c|c|}
\hline & N (\%) \\
\hline Düzenli egzersiz yapmak & $79(31.6)$ \\
\hline Sağlıkı beslenmek & $77(30.8)$ \\
\hline Düzenli sağlık kontrolü yaptırmak & $43(17.2)$ \\
\hline Sigara ve alkol içmemek, bırakmak & $36(14.4)$ \\
\hline Sağlıklı bir kiloya sahip olmak & $15(6.0)$ \\
\hline
\end{tabular}


oran önceki araştırmalara kıyasla çok yüksek olmamakla beraber, katılımcıların yaş ortalamasının düşük olması dikkate alındığında, ilerleyen yaşla beraber bu riskin artabileceği düşünülmektedir.

Ayrıca yoğun iş temposu, uzun süreli oturma ve boş zamanlarda düşük düzeyde fiziksel aktivite katılımı KVH ve diabet gelişimi için önemli risk faktörleri olarak kabul edilmektedir. (Uffelen, Wong, Chau ve ark, 2010; Puhkala, Kukkonen-Harjula, Aittasalo ve ark, 2016)

Taşımacılık sektörünün büyük çoğunluğunda erkeklerin çalıştığı ve diğer sektörlere kıyasla, fazla kilolu olma ve obezite oranının daha yüksek olduğu belirtilmektedir. (Department of $\mathrm{He}^{-}$ alth and Ageing. 2010). Martin ve arkadaşlarının raporuna göre dünya çapında kamyon ve otobüs sürücülerinin \% 57-87'sinin fazla kilolu ve obezdir (Martin ,Church, Bonnell ve ark, 2009). Shin ve ark.' nın 443 erkek otobüs şoförünü değerlendirdikleri çalışmalarında \% 53.9'unun fazla kilolu olduğunu belirtmişlerdir (Shin, Lee, Song ve ark. 2013).

Araştırmamıza katılan minibüs şoförleri, kalp hastalıklarının gelişiminde rol oynayan değiştirilebilir risk faktörleri açısından incelenmiştir. Şoförlerin büyük çoğunluğu kilolu veya obezdi ve yaklaşık yarısının düzenli sigara içmesi dikkat çekiciydi. Sağlıklı yaşam tarzının en önemli öğesi düzenli olarak fiziksel aktivitelere katılımdır. Egzersizin yer aldığı aktif bir yaşam, KVH gelişim intimalini azaltmanın yanı sıra, KVH gelişiminde rolü olduğu bilinen, diabet, hipertansiyon, obesite gibi sağlık problemlerinin de önlenmesine katkıda bulunmaktadır (Mendis, Puska ve Norrving, 2011). Dolayısı ile araştırmamızda katılımcıların fiziksel aktivite alışkanlığı daha kapsamlı değerlendirilmiştir. Düzenli egzersiz yapıyor musunuz sorusuna \% 88 katılımcı olumsuz yanıt vermiştir. Şoförlerin tümüne uygulanan UFAA ile fiziksel aktivite düzeyinin daha objektif nitelendirilmesi mümkün olmuştur.

$\mathrm{KVH}$ gelişiminde rol oynayan risk faktör düzeyleri ile ilgili sonucumuzu daha sağlıklı tartışabilmek için ülkemizde yapılan benzer çalışmalar araştırı mıştır. Ancak çalışmaların sınırlı olduğu görülmüştür (Keskin, Kütük, Özmen ve ark. 2012; Uludağ, Cevizci, Tekin ve ark. 2015). Keskin ve arkadaşları, Ankara'da taksi şoförlerinin sağlıkı beslenme, sigara, düzenli uyku, alkol kullanımı, fiziksel aktivite benzeri sağlıklı ve riskli yaşam davranışlarını değerlendirmişlerdir. 371 taksi şoförünün sadece birinin sağlıklı davranışların tamamına sahip olduğunu bunun yanı sıra, 11 şoförün hiçbir sağılılı davranışa sahip olmadığını göstermişlerdir (Keskin, Kütük, Özmen ve ark. 2012). Uludağ ve arkadaşlarının çalışmasında ise, taksi ve otobüs şoförlerinde çalışma koşulları ile sağlık durumlarının arasındaki ilişki gözden geçirilmiştir. Çalışmanın sonucunda şoförlerin stres ve immobil olmak gibi birçok KVH riskine sahip oldukları ve hipertansiyon prevalansının \%9,2, diabetes mellitusun $\% 1,8$ ve obezitenin $\% 49,4$ ' olduğu rapor edilmiştir (Uludağ, Cevizci, Tekin ve ark. 2015) Hipertansiyon ve fiziksel inaktivite yönünden sonuçlarımız bu raporla uyumludur .

Araştırmamız kapsamında şoförlerin kalp damar hastalıklarının önlenmesi konusundaki düşüncelerine de yer verilmiştir. Katılımcıların büyük çoğunluğu, bu hastalıkların önlenebilir olduğunu belirtmiştir. Kalp hastalıklarının önlenmesinde en önemli davranışın ne olduğu sorgulandığında; \% 32 ye yakın bir oranla düzenli egzersiz yapmak en ön plana çıkmıştır. Ancak düzenli egzersizin önemini bilmelerine rağmen, fiziksel inaktivite oranının yüksek olması mesleğin zor çalışma koşulları veya şoförlerin eğitim düzeyi ile ilişkili olabileceği düşünülmektedir.

Sonuç olarak, Kırıkkale ilinde minibüs şoförleri arasında genç yaş ortalamasına rağmen, kalp damar hastalıkları, obesite, hipertansiyon gibi sorunlara rastlanmıştır. Tüm bu sağlık sorunlarının önlenebilmesinde sağlıklı yaşam tarzının benimsenmesi en önemli rolü oynamaktadır. Sağlıklı yaşam tarzının öğeleri ise düzenli egzersiz yapmak, sigara kullanmamak ve sağlıklı beslenmektir. Ancak çalışmaya katılan şoförlerin önemli bir çoğunluğunun inaktif bir yaşam sürmesi ve sigara içmesi dikkati çekmektedir. Minibüs şoförleri gibi inaktif ve stressli çalışma koşulları olan meslek gruplarında, kronik hastalıklara yönelik risklerin belirleyen araştırmalara intiyaç olduğu düşünülmektedir. Çalışmaların sonuçları doğrultusunda, ilgili risklerin azaltılması ve hastalıkların önlenmesi konusunda çalışanların bilgi ve bilinç düzeylerinin artıran müdahaleler planlanabilecektir. 


\section{KAYNAKLAR}

Alpar, R. (2012). Spor, sağlık ve eğitim bilimlerinden örneklerle uygulamalı istatistik ve geçerlik-güvenirlik. Ankara: Detay Yayıncılık.

Amine, E., Baba, N., Belhadj, M., Deurenbery-Yap, M., Djazayery, A., Forrester, T., \& et al. (2002). Diet, nutrition and the prevention of chronic diseases: report of a Joint WHO/FAO Expert Consultation. World Health Organization.

Apantaku-Onayemi, F., Baldyga, W., Amuwo, S., Adefuye, A., Mason, T., Mitchell, R., \& Blumenthal, D. S. (2012). Driving to better health: Cancer and cardiovascular risk assessment among taxi cab operators in Chicago. $J$ Health Care Poor Underserved, 23(2), 768.

Arslan, C., Koz, M., Gür, E., \& Mendeş, B. (2003). Üniversite öğretim üyelerinin fiziksel aktivite düzeyleri ve sağlık sorunları arasındaki ilişkinin araştırılması. FÜ Sağıı Bil Dergisi, 17 (4), 249-258.

Australia, M. (2010). Department of Health and Ageing. National Health Survey for the Working Population. Canberra (AUST): Commonealth of Australia.

Beck, A. T, Epstein, N., Brown, G., \& Steer, R. A. (1988). An inventory for measuring clinical anxiety: Psychometricproperties. J Consult Clin Psychol, 56, 893-897.

Bigert, C., Gustavsson, P., Hallqvist, J, et al. (2003). Myocardial infarction among professional drivers. Epidemiology, 14 (3), 333-339.

Callow, A. D. (2006). Cardiovascular disease 2005. Vascul Pharmacol, 45(5), 302-307.

Constitution of the World Health Organization, WHO, Basic Documents, Forty-fifth edition, Supplement, October 2006, http://www.who.int/governance/eb/ who_ constitution_en.pdf. Erişim tarihi:20.12.2016.

Department of Health and Ageing. (2010) Analysis of 2007/08 National Health Survey for the Working Population. Canberra (AUST): Commonealth of Australia.

Hattori, M. (1988). Epidemiological study of ischemic heart diseases in taxi drivers. National Institute of Public Health (in Japanese).

Hattorı, M. (1989). Long-term follow-up of ischemic heart disease in taxi drivers and the influence of taxi driving on their cardiovascular and autonomic nerve functions I. J Sci of Labour, 65, 580-589.

Hirata, R. P., Sampaio, L. M. M., LeitaoFilho, F. S. S., Braghiroli, A., Balbi, B., Romano, S., \& et al. (2012). General characteristicsand risk factors of cardiovascular disease among inter state bus drivers. Scientific World J, 2012.

Keskin, E. T., Kütük, F., Özmen, B. B., Özyörük, E., Yazır, Y., \& Aslan, D. (2012). Ankara'da bazı semt duraklarında çalışan taksi şoförlerinin sağlıklı/riskli yaşam davranışları. STED, 21(4), 222.

Martin, B. C, Church, T. S, Bonnell, R., Ben-Joseph, R., \& Borgstadt, T. (2009). The impact of overweight and obesity on the direct medical costs of truck drivers. J Occup Environ Med, 51 (2), 180-4.

Mendis, S., Puska, P., \& Norrving, B. (2011). Global Atlas on cardiovascular disease prevention and control. Geneva: World Health Organization.

Mitka, M. (2004). Heartdisease a global health threat. JAMA, 291(21), 2533.

Mutangadura, Gladys B (ed.). Reducing risks, promotinghealthy life World. Health Report 2002; Geneva, World Health Organization, 2002.

Onat, A., Keleş, I.., Çetinkaya, A., Başar, Ö., Yıldırım, B,. Erer, B., ve ark. (2001). On yıllık TEKHARF çalışması verilerine göre Türk erişkinlerinde koroner kökenli ölüm ve olayların prevalansı yüksek. Türk Kardiyol Dern Arş, 29, 8-19.

Puhkala, J., Kukkonen-Harjula, K., Aittasalo, M., Mansikkamäki, K., Partinen, M., Hublin, C., \& et al. (2016). Lifestyle counseling in overweight truck and bus drivers-Effects on dietary patterns and physical activity. Prev Med Rep, 4, 435-440.

Sağlam, M., Arikan, H., Savci, S., Inal, I. D., Bosnak, G. M., Karabulut, E., ve ark. (2010). International physical activity questionnaire: reliability and validity of the Turkish version. Percept Mot Skills, 111, 278-84.

Shin, S. Y., Lee, C. G., Song, H. S., Kim, S. H., Lee, H. S., Jung, M. S., et al. (2013). Cardiovascular disease risk of bus drivers in a city of Korea. AOEM, 25(1), 1.

Sofi, F., Cesari, F., Abbate, R., Gensini, G. F., \& Casini, A. (2008). Adherenceto Mediterranean diet and health status: meta-analysis. BMJ, 337, 1331.

Ueda, T., Hashimoto, M., Yasui, I., Sunaga, M., Higashida, T., \& Hara, I. (1989). [A questionnaire study on health of taxi drivers--relations to work conditions and daily life]. Jpn J IndHealth, 31(3), 162-175.

Uludağ, A., Cevizci, S., Tekin, M., Ertekin, Y. H., Sevim, S., Babaoğlu, Ü., et al. (2015). Taksi ve otobüs şoförlerinin çalışma koşullarının sağlık durumlarına etkisi, çanakkale; toplum tabanlı çalışma. J Clin Anal Med, 6(6), 835-838.

Ulusoy, M., Sahin, N. H., \& Erkmen, H. (1998). Turkish version of the Beck Anxiety Inventory: psychometric properties. J Cogn Psychother, 12(2), 163-172.

Van Uffelen, J. G., Wong, J., Chau, J. Y., van der Ploeg, H. P., Riphagen, I., Gilson, N. D., et al. (2010). Occupational sitting and health risks: a systematic review. Am J Prev Med, 39(4), 379-388.

Zheng, X., Bai, L., Wan, F., Wang, Y., Sang, S., et al. (2014). Perceptions of heat risk tohealth: A qualitativestudy of professionalbusdriversandtheirmanagers in Jinan, China. Int J Environ Res Public Health, 11:1520-1535. 